\title{
Adjustments to the MODIS Terra radiometric calibration and polarization sensitivity in the 2010 reprocessing
}

\author{
Gerhard Meister ${ }^{a}$, Bryan A. Franz ${ }^{a}$ \\ ${ }^{a}$ NASA, Ocean Biology Processing Group, Code 614.2, Goddard Space Flight Center, \\ Greenbelt, MD 20771, USA;
}

\begin{abstract}
The Moderate-Resolution Imaging Spectroradiometer (MODIS) on NASA's Earth Observing System (EOS) satellite Terra provides global coverage of top-of-atmosphere (TOA) radiances that have been successfully used for terrestrial and atmospheric research. The MODIS Terra ocean color products, however, have been compromised by an inadequate radiometric calibration at the short wavelengths. The Ocean Biology Processing Group (OBPG) at NASA has derived radiometric corrections using ocean color products from the SeaWiFS sensor as truth fields. In the R2010.0 reprocessing, these corrections have been applied to the whole mission life span of 10 years. This paper presents the corrections to the radiometric gains and to the instrument polarization sensitivity, demonstrates the improvement to the Terra ocean color products, and discusses issues that need further investigation. Although the global averages of MODIS Terra ocean color products are now in excellent agreement with those of SeaWiFS and MODIS Aqua, and image quality has been significantly improved, the large corrections applied to the radiometric calibration and polarization sensitivity require additional caution when using the data.
\end{abstract}

Keywords: remote sensing, scanners, on-orbit calibration, polarization

\section{INTRODUCTION}

Two units of the Moderate-Resolution Imaging Spectroradiometer (MODIS) ${ }^{1}$ are currently in operation, providing global coverage of top-of-atmosphere (TOA) radiances from $412 \mathrm{~nm}$ to $14200 \mathrm{~nm}$. The first unit was launched in December 1999 on NASA's Earth Observing System (EOS) Terra satellite, the second on the Aqua satellite in May 2002. MODIS has 36 spectral bands on four different focal planes. The Ocean Biology Processing Group (OBPG) at NASA uses bands 8-16 (nominal spatial resolution of $1 \mathrm{~km}$ at nadir view) with center wavelengths from $412 \mathrm{~nm}$ to $869 \mathrm{~nm}$ to produce the standard ocean color data products. ${ }^{2}$ Recently, the OBPG has added the processing of the higher spatial resolution bands 1, 3, and 4. For the standard products, the spatial resolution is reduced to $1 \mathrm{~km}$ (users can obtain higher spatial resolution by processing the data themselves using the SeaDAS package). The fundamental ocean color products are water-leaving radiances from bands 8-14, see table 1. Bands 15 and $16(748 \mathrm{~nm}$ and $869 \mathrm{~nm})$ are used in the atmospheric correction process, i.e. to convert TOA radiances to water-leaving radiances. All ocean color products are derived from the water-leaving radiances. More information on the ocean color products provided by the OBPG can be found at their website: http:oceancolor.gsfc.nasa.gov.

Each MODIS ocean color band has 10 independent detectors, and each of these detectors needs to be calibrated and characterized separately. Both MODIS instruments are calibrated using on-board calibrators ${ }^{3}$ and lunar irradiances. ${ }^{4}$ For MODIS Terra, these calibrations have not been sufficient to produce high quality ocean color products. ${ }^{5}$ The OBPG has developed a cross calibration method to improve the MODIS Terra characterization for bands 8-14, using SeaWiFS ${ }^{6}$ water-leaving radiances as truth fields. ${ }^{7}$ This paper presents the derived corrections and demonstrates the impact of those corrections on the MODIS Terra ocean color products.

Further author information:

G.M.: E-mail: Gerhard.Meister@nasa.gov

Table 1. MODIS ocean color bands, their center wavelengths $\lambda$, and the center wavelengths of the corresponding SeaWiFS bands.

\begin{tabular}{|c|c|c|c|c|c|c|c|c|c|c|c|c|}
\hline MODIS band number & 1 & 3 & 4 & 8 & 9 & 10 & 11 & 12 & 13 & 14 & 15 & 16 \\
\hline MODIS $\lambda[\mathrm{nm}]$ & 645 & 469 & 555 & 412 & 443 & 488 & 531 & 547 & 667 & 678 & 748 & 869 \\
\hline SeaWiFS $\lambda[\mathrm{nm}]$ & & & & 412 & 445 & 490 & 510 & 555 & 670 & & 765 & 865 \\
\hline
\end{tabular}




\section{VICARIOUS CALIBRATION METHOD}

The standard polarization correction equation for an uncalibrated instrument ${ }^{8}$ is

$$
L_{m}=M_{11} L_{t}+M_{12}\left(Q_{t} \cos 2 \alpha+U_{t} \sin 2 \alpha\right)+M_{13}\left(-Q_{t} \sin 2 \alpha+U_{t} \cos 2 \alpha\right)+M_{14} V_{t}
$$

where $\left(L_{t}, Q_{t}, U_{t}, V_{t}\right)$ is the Stokes vector at the TOA, $L_{m}$ is the measured radiance, $M_{11}$ to $M_{14}$ are the elements of the first line of the Mueller Matrix, and $\alpha$ is a rotation angle to adjust for different reference frames of the modeled atmospheric polarization and the instrument. Since $V_{t}$, the circular polarization component, is very close to zero at the TOA, $M_{14}$ is irrelevant. The polarization sensitivity parameters $M_{12}$ and $M_{13}$ were determined prelaunch at scan angles from $-45^{\circ}$ to $+45^{\circ}$, for each band, mirror side, and detector. ${ }^{9}$ The small variations of these parameters with detector were considered suspect and not applied in the ocean color processing. ${ }^{10}$

The cross calibration method has been described by Kwiatkowska et al., ${ }^{7}$ so here we provide only a brief summary. The correction parameters $\mathrm{M}_{11}, \mathrm{M}_{12}$, and $\mathrm{M}_{13}$ were calculated relative to the calibration (version 6.1.6.2) provided by the MODIS Characterization Support Team (MCST). For a given day, the level 3 waterleaving radiances from SeaWiFS are used to predict the top-of-atmosphere (TOA) radiances as seen by MODIS on that day, using the vicarious calibration technique described in Franz et al., 2007, ${ }^{12}$ and the atmospheric correction model consistent with the R2010.0 reprocessing. Thus, all relevant components of the Stokes vector $\left(L_{t}, Q_{t}, U_{t}\right)$ can be modeled. This allows the estimation of the radiometric calibration parameters $\mathrm{M}_{11}$ as well as the polarization sensitivity parameters $\mathrm{M}_{12}$ and $\mathrm{M}_{13}$ by minimizing differences between the left-hand and right-hand side of eq.1 over many observations.

The parameters $\mathrm{M}_{11}, \mathrm{M}_{12}$, and $\mathrm{M}_{13}$ are derived simultaneously by constructing a matrix of thousands of instances of eq. 1, each line corresponding to a matchup of one MODIS Terra measurement $\left(L_{m}\right)$ with one predicted TOA Stokes vector.

In the correction process, $\mathrm{M}_{11}$ is applied first, i.e. $\mathrm{M}_{12}$ and $\mathrm{M}_{13}$ need to be applied relative to a calibrated instrument. The polarization correction equation for a calibrated instrument ${ }^{8}$ is thus

$$
L_{m}=L_{t}+m_{12}\left(Q_{t} \cos 2 \alpha+U_{t} \sin 2 \alpha\right)+m_{13}\left(-Q_{t} \sin 2 \alpha+U_{t} \cos 2 \alpha\right)+m_{14} V_{t}
$$

with

$$
\begin{aligned}
& m_{12}=\frac{M_{12}}{M_{11}} \\
& m_{13}=\frac{M_{13}}{M_{11}}
\end{aligned}
$$

The modeled TOA radiances are compared to the radiances measured by MODIS for every scan angle, mirror side, and detector. This means that the instrument characterization parameters $\left(\mathrm{M}_{11}, \mathrm{~m}_{12}, \mathrm{~m}_{13}\right)$ can be derived as a function of scan angle, mirror side, and detector. To reduce noise, the scan angle dependence is modeled by a cubic function for $\mathrm{M}_{11}$, and as a linear function for $\mathrm{m}_{12}$ and $\mathrm{m}_{13}$.

The method is currently not applied to the near-infrared (NIR) bands. Fig. 1 shows that the globally averaged aerosol optical thickness (AOT) and the aerosol spectral properties (angstrom) do not demonstrate a strong temporal trend (compare to the angstrom trends of MODIS Aqua and SeaWiFS shown in Meister et al. ${ }^{13}$ ), which suggests that the MCST calibration of the NIR bands of MODIS Terra is acceptable.

The retrieval of the instrument characterization parameters is repeated for one day in every month of the mission. This results in a time series for the instrument characterization parameters. Examples are shown below in Fig. 2. The parameters are retrieved as a function of scan angle (third order polynomial) for each day.

The retrievals for the parameter $\mathrm{m}_{13}$ show a seasonal oscillation that cannot be explained. (Meister et al.,2011 ${ }^{14}$ compares the $\mathrm{m}_{13}$ from MODIS Terra and Aqua for bands 13 and 14, the phasing of the seasonal oscillation is opposite for the two sensors.) However, no trend is seen in the $\mathrm{m}_{13}$ over the Terra mission time frame (see Fig. 2), so it was decided to hold the $\mathrm{m}_{13}$ fixed at the prelaunch values when deriving $M_{11}$ and $m_{12}$.

To reduce noise, polynomials (as a function of time) were fitted to the retrievals of $\mathrm{M}_{11}$ and $\mathrm{m}_{12}$ as described in table 2. The choices made in table 2 are based on the variability of the respective parameter in the given time 

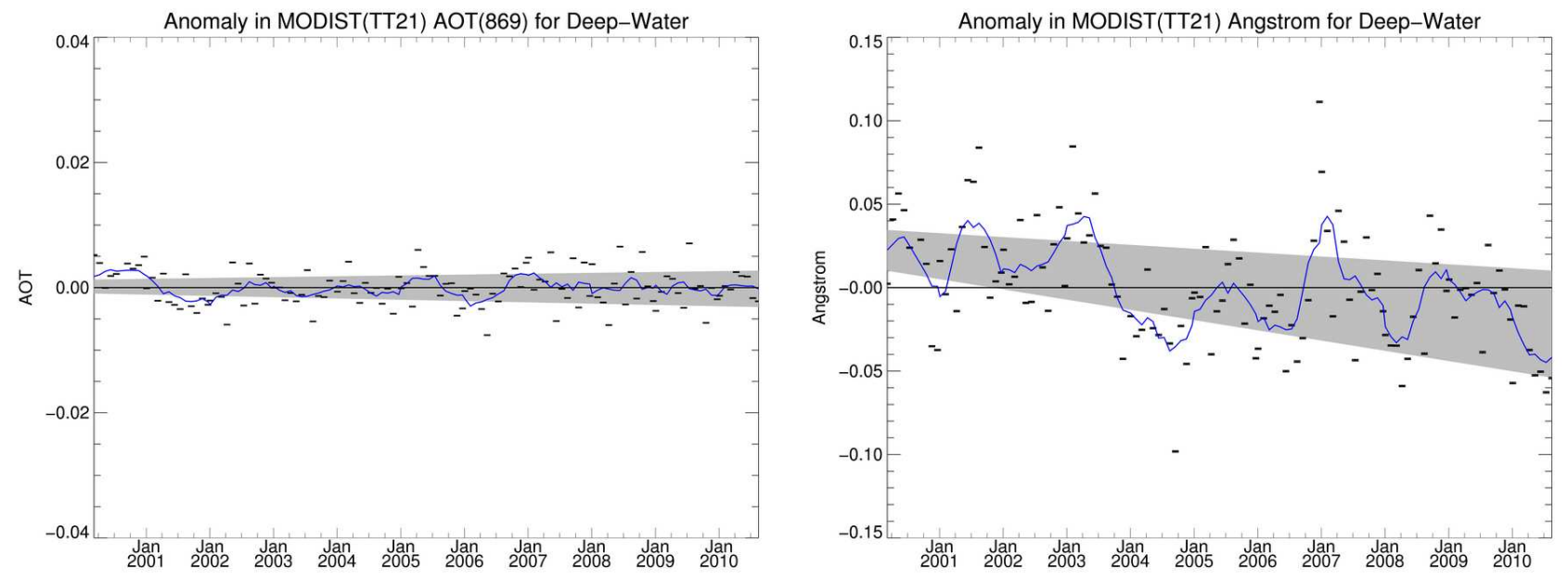

Figure 1. Anomaly plots of the MODIS Terra AOT (left) and angstrom (right). The methodology to create these anomaly plots is explained in Franz et al. ${ }^{5}$

periods. Bands 11-14 have a single polynomial for the whole mission, bands 8-10 have independent polynomials in three different time periods. The second period of bands 8-10 is a bridge between the first period and the third period (a linear fit to the end point and start point of the respective period) to ensure a seamless time series. The end of the first period was chosen to coincide with the solar diffuser door event. ${ }^{5}$ For bands 1,3 , and 4 , the corrections were derived by interpolating the smoothed $\mathrm{M}_{11}$ and $\mathrm{m}_{12}$ coefficients spectrally from the nearest $1 \mathrm{~km}$ ocean color band (bands 8-14).

Fitting the polynomials of table 2 to the retrieved $M_{11}$ and $m_{12}$ leads to the expectation that MODIS Terra will follow the long-term trends of SeaWiFS and MODIS Aqua, but not necessarily the short term trends.

Note that the temporal fitting is complicated by the fact that the correction is applied in the form of a polynomial (third degree) as a function of scan angle. Temporal fits evaluated at various scan angles may not (and generally do not) result exactly in a third degree polynomial as a function of scan angle. The current implementation of the fitting process involves finding the optimum temporal trends (using the polynomials outlined in table 2) for tie points at 15 different scan angles, and then fitting a scan angle dependence to these optimum trends for each month. This scan angle dependence is applied in the correction, with linear interpolation in time (between months). Fig. 3 provides an example. This figure also clearly shows a seasonal oscillation of the retrieved $m_{12}$, which is eliminated in the smoothed results.

The smoothed $M_{11}$ and $m_{12}$ are applied as a correction in the MODIS Terra ocean color processing according to eq. 1. The derived corrections for both mirror sides and all 10 detectors are shown in Figs. 4 and 5 for band 8 (the band with the largest variations). It can be seen that the agreement between mirror sides and detectors is best for the lunar view angle. This indicates that the MCST calibration derived from lunar trending is accurate. The magnitude of the corrections and the variation with detector and mirror side are largest at the end of scan. This can be explained by the expected increase of the MODIS polarization sensitivity at the end of $\operatorname{scan}^{7}$ and the unavailability of a calibration source at the end of the scan. ${ }^{5}$

The same type of plot is shown in Figs. 6 and 7 for band 10. The mirror side and detector dependency that

Table 2. Degree of polynomial (function of time) used for the smoothing of retrieved $\mathrm{M}_{11}$ and $\mathrm{m}_{12}$.

\begin{tabular}{|l|l|l|l|}
\hline Time period & Bands 8-10 & Bands 11-12 & Bands 13-14 \\
\hline Feb. 2000 - May 2003 & linear & fifth degree & third degree \\
\cline { 1 - 2 } May 2003 - May 2004 & linear & \\
\cline { 1 - 4 } May 2004 - Aug. 2010 & $\begin{array}{l}\text { fifth degree, except for } \mathrm{m}_{12} \\
\text { of band 10 (second degree) }\end{array}$ & & \\
\hline
\end{tabular}



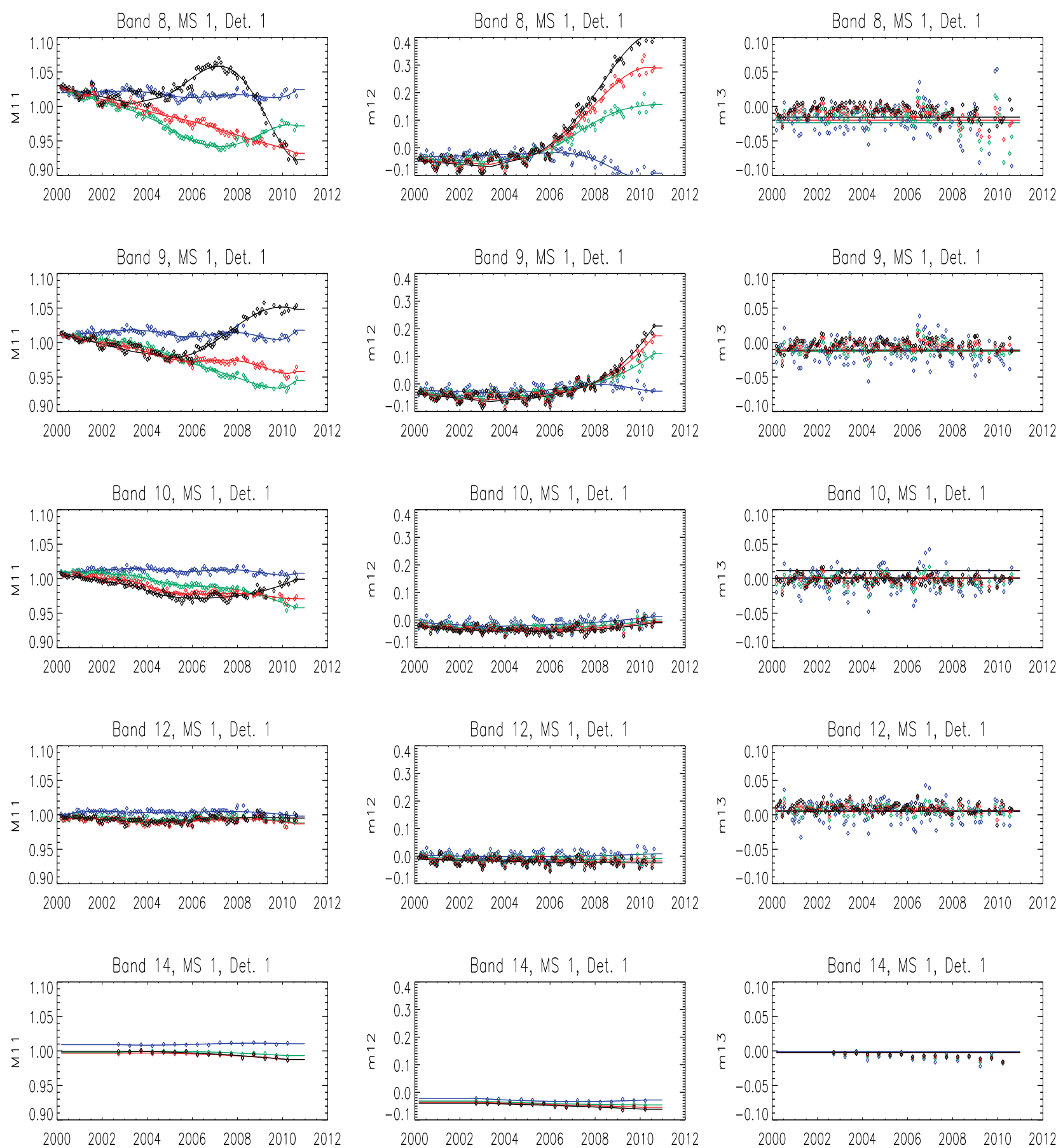

Figure 2. $\mathrm{M}_{11}, \mathrm{~m}_{12}, \mathrm{~m}_{13}$ for mirror side 1, detector 1 of MODIS Terra as a function of time for four bands and at four different scan angles: beginning of scan (frame 22, blue), nadir (frame 675, green), solar diffuser view angle (frame 979, red), and end of scan (frame 1250, black). $\mathrm{m}_{13}$ is shown when retrieved simultaneously with $\mathrm{M}_{11}$ and $\mathrm{m}_{12}, \mathrm{M}_{11}$ and $\mathrm{m}_{12}$ are shown when retrieved with $\mathrm{m}_{13}$ set to prelaunch values. Symbols are the retrievals (once a month for retrievals relative to SeaWiFS, twice a year for retrievals relative to MODIS Aqua). Solid lines are temporal fits to the retrievals for $\mathrm{M}_{11}$ and $\mathrm{m}_{12}$, prelaunch values for $\mathrm{m}_{13}$. 

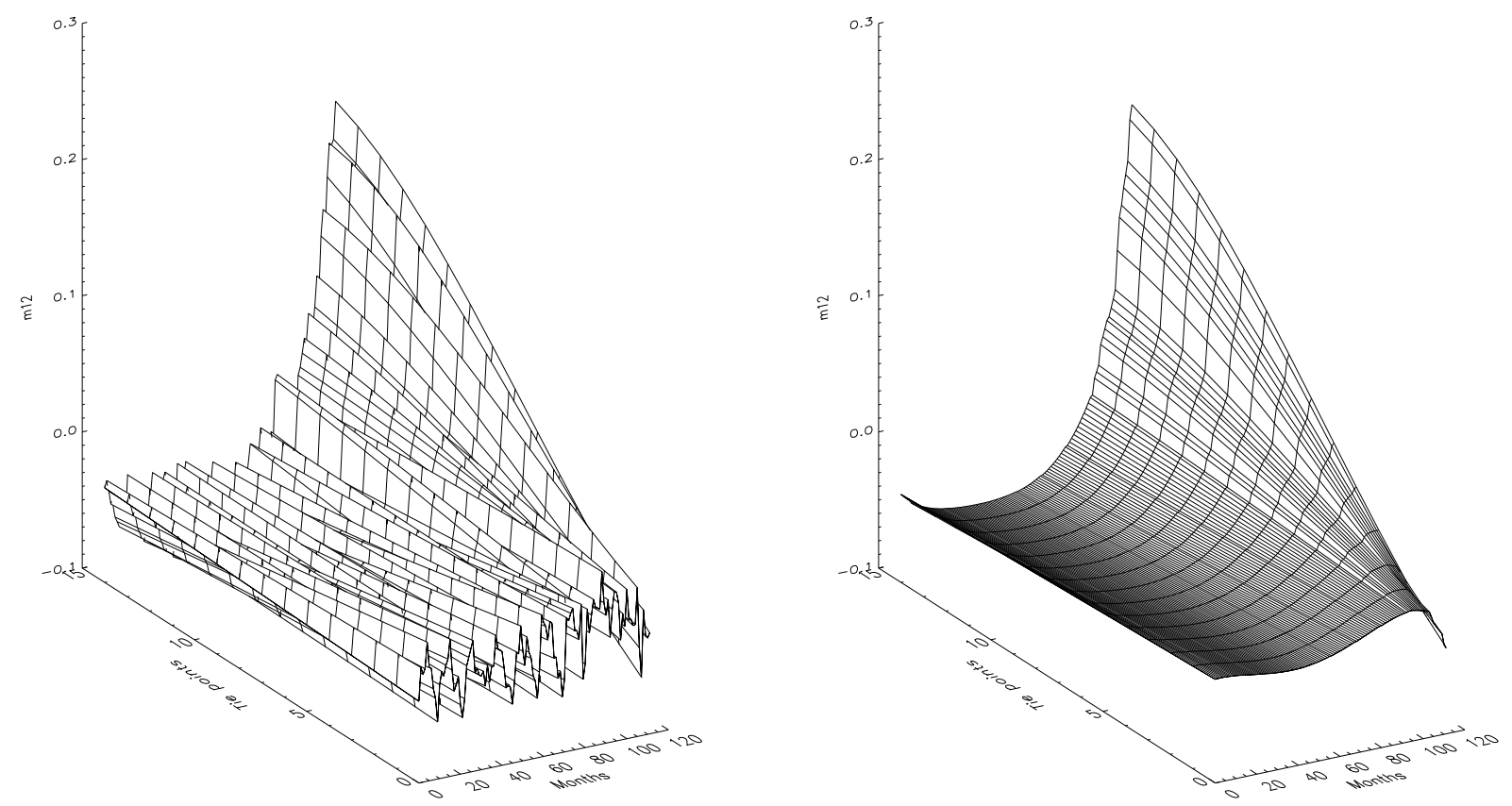

Figure 3. Left: retrieved $\mathrm{m}_{12}$ for band 9, detector 1 , mirror side 1 , evaluated at 15 tie points (tie point 0 : frame 1 , tie point 14: frame 1354) and at 122 months. Right: smoothed result.

can clearly be seen for band 8 (and 9, not shown here) is much less pronounced. Bands at higher wavelengths require corrections that are of a much smaller magnitude (less than $1 \%$ for $\mathrm{M}_{11}$ for bands 11-14) with even smaller mirror side or detector variations.

SeaWiFS has only one band in the red $(670 \mathrm{~nm}$, see table 1$)$, so it is not possible to independently correct MODIS Terra bands $13(667 \mathrm{~nm})$ and $14(678 \mathrm{~nm})$ or account for potential geophysical changes in fluorescence at $678 \mathrm{~nm}$. Therefore, it was decided to use MODIS Aqua's bands 13 and 14 as truth source for the correction of MODIS Terra bands 13 and 14. For the period without overlap of the Aqua and Terra missions (2000 to early 2002), the corrections are set to the first value in 2002 where Aqua data is available. As can be seen in Fig. 2, the early part of the MODIS Terra mission does not require significant corrections for the red bands, so the lack of overlap is not a problem.

After application of the retrieved $\mathrm{M}_{11}$ and $\mathrm{m}_{12}$, a final vicarious calibration ${ }^{12}$ is applied using in-situ data from the Marine Optical Buoy ${ }^{15}$ (MOBY). This is done to remove any residual bias in the sensor-calibrationatmospheric-correction system.

\section{OCEAN COLOR PRODUCTS BEFORE AND AFTER CORRECTION}

The OBPG processed subsets of the MODIS Terra data to evaluate the effect of the corrections derived in the previous section. The test without the correction is called 'TT20', with the corrections 'TT21'. All the data from every 8th 4-day period is processed for each test, the global average water-leaving reflectances (Rrs) and chlorophyll are shown in Fig. 8. It can be seen that there is a strong downward trend in the shorter wavelength reflectances and a very strong upward trend in the chlorophyll product before the correction. After application of the corrections, the trends have been significantly reduced. For band $3(469 \mathrm{~nm})$, a strong downward trend has become a moderate upward trend, indicating that the spectral interpolation approach resulted in an overcorrection in this case. 

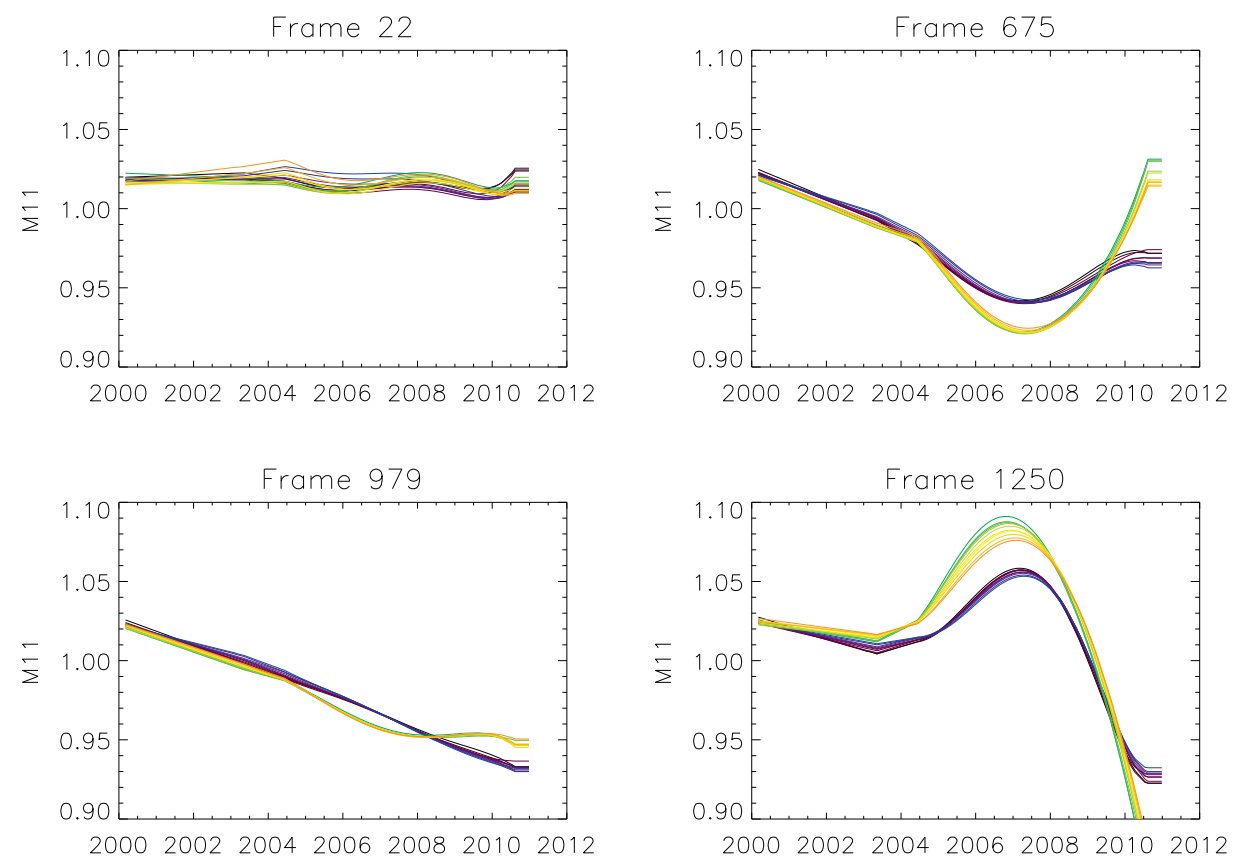

Figure $4 . \mathrm{M}_{11}$ for band 8 for both mirror sides and all detectors. Blue to black: detectors 1-10, mirror side 1. Green to orange: detectors 1-10, mirror side 2. The scan angles (or frames) are the same as those shown in Fig. 2 and are given in the title of each plot.
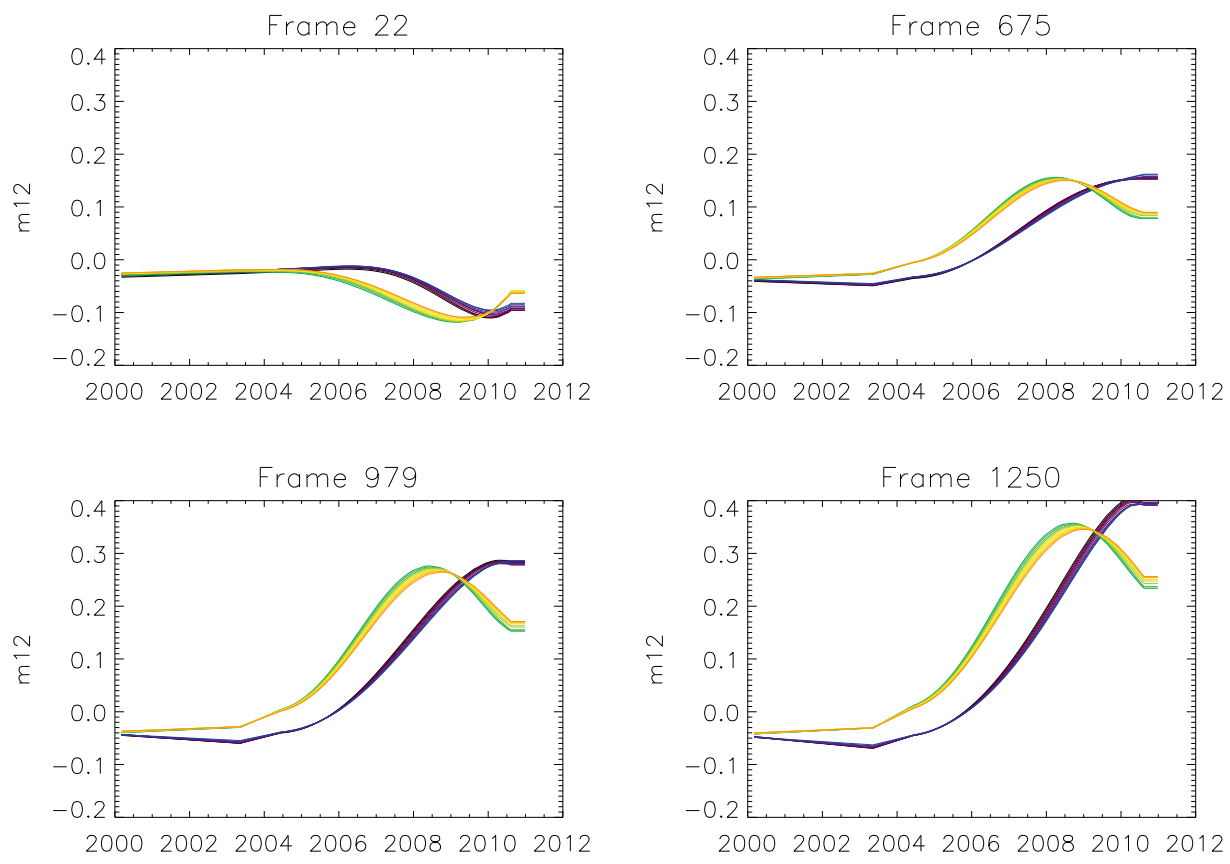

Figure $5 . \mathrm{m}_{12}$ for band 8 for both mirror sides and all detectors. Black to blue: detectors 1-10, mirror side 1 . Green to orange: detectors 1-10, mirror side 2. The scan angles (or frames) are the same as those shown in Fig. 2 and are given in the title of each plot. 

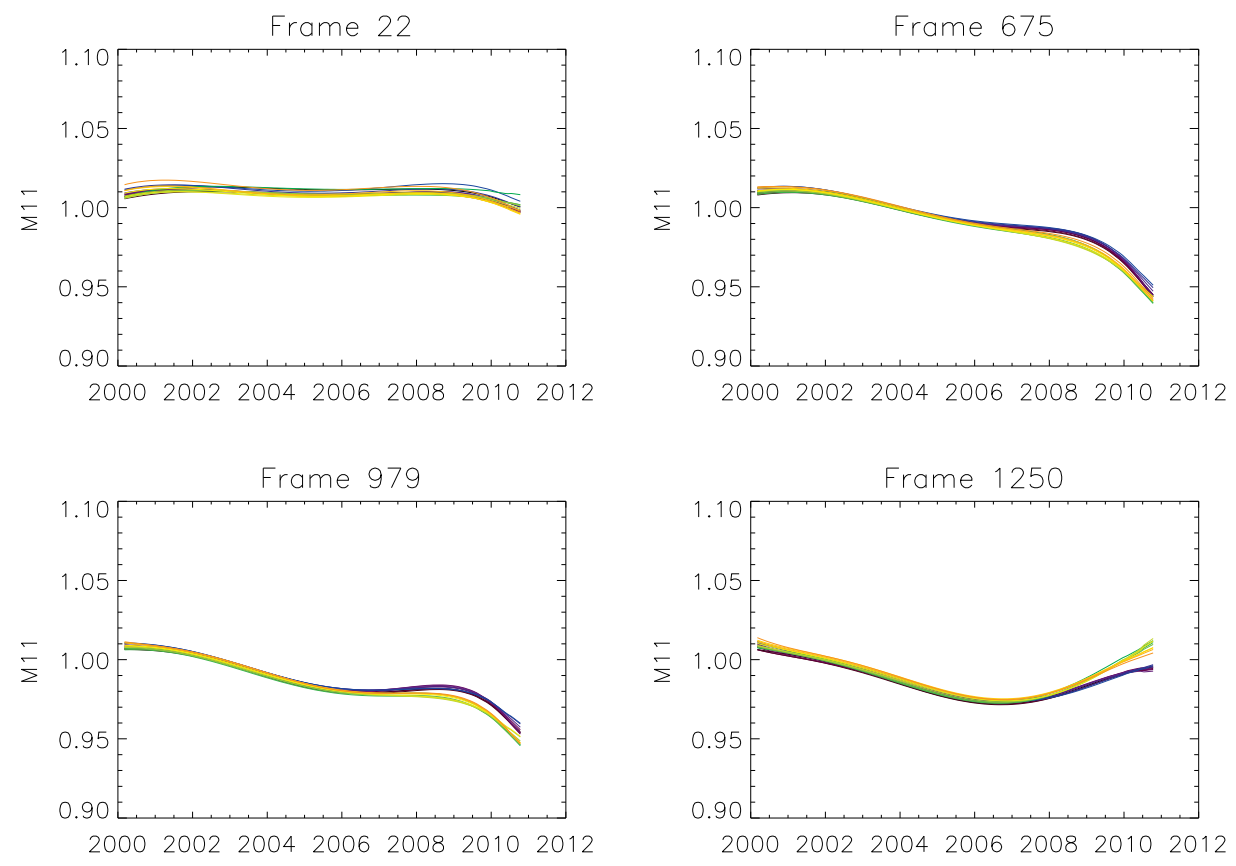

Figure 6. $\mathrm{M}_{11}$ for band 10 for both mirror sides and all detectors. Blue to black: detectors 1-10, mirror side 1. Green to orange: detectors 1-10, mirror side 2. The scan angles (or frames) are the same as those shown in Fig. 2 and are given in the title of each plot.
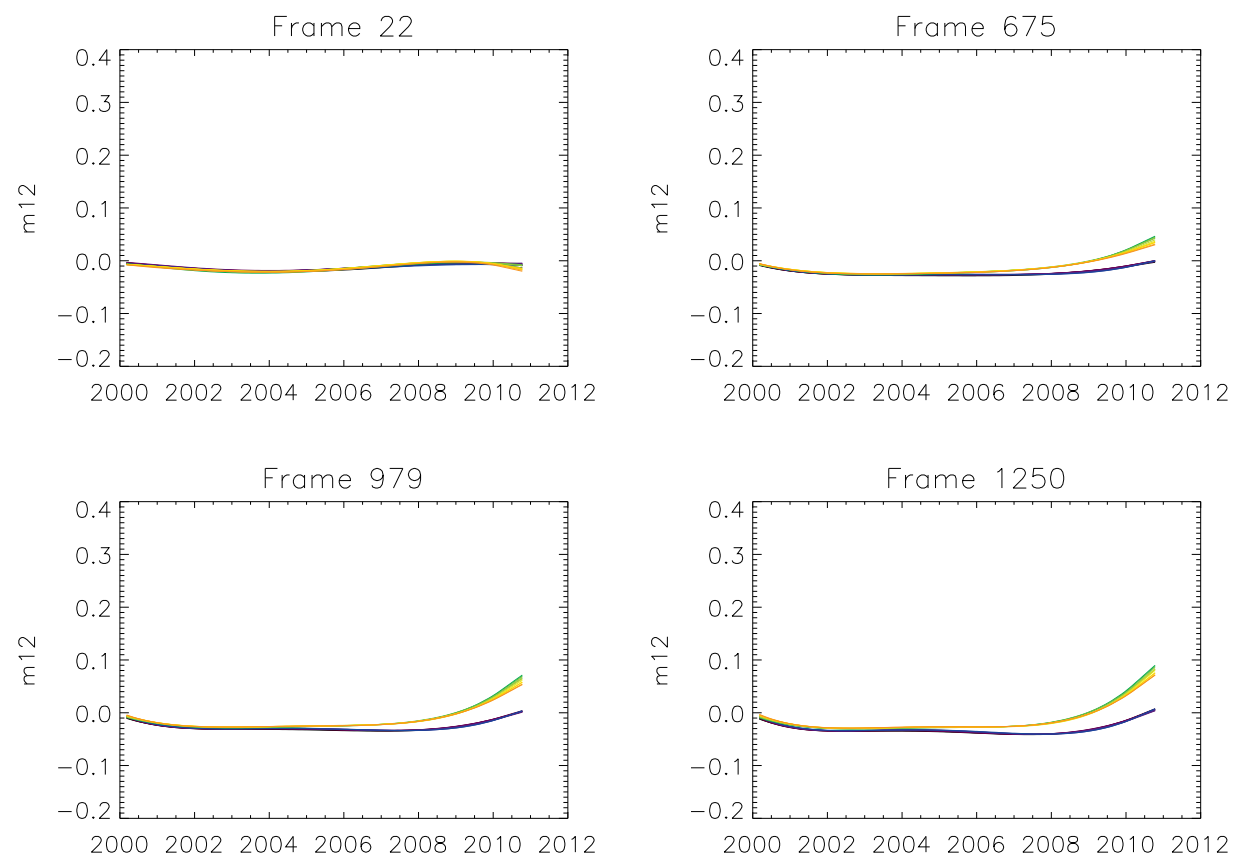

Figure 7. $\mathrm{m}_{12}$ for band 10 for both mirror sides and all detectors. Black to blue: detectors 1-10, mirror side 1. Green to orange: detectors 1-10, mirror side 2. The scan angles (or frames) are the same as those shown in Fig. 2 and are given in the title of each plot. 

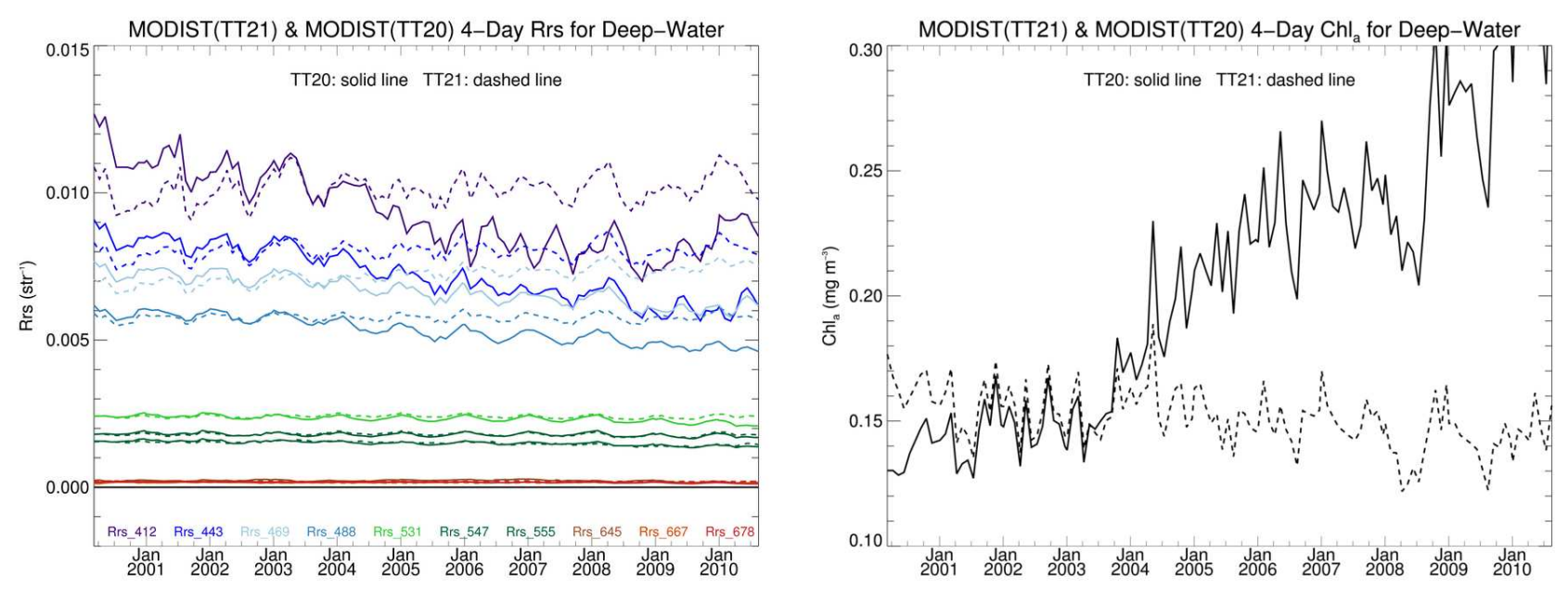

Figure 8. Left: Remote sensing reflectance averaged over global deep water without (solid lines) and with (dashed lines) corrections. Solid (dashed) lines from top to bottom: 412nm, 443nm, 469nm, 488nm, 531nm, etc. Right: Chlorophyll-a concentration averaged over global deep water without (solid lines) and with (dashed lines) corrections.
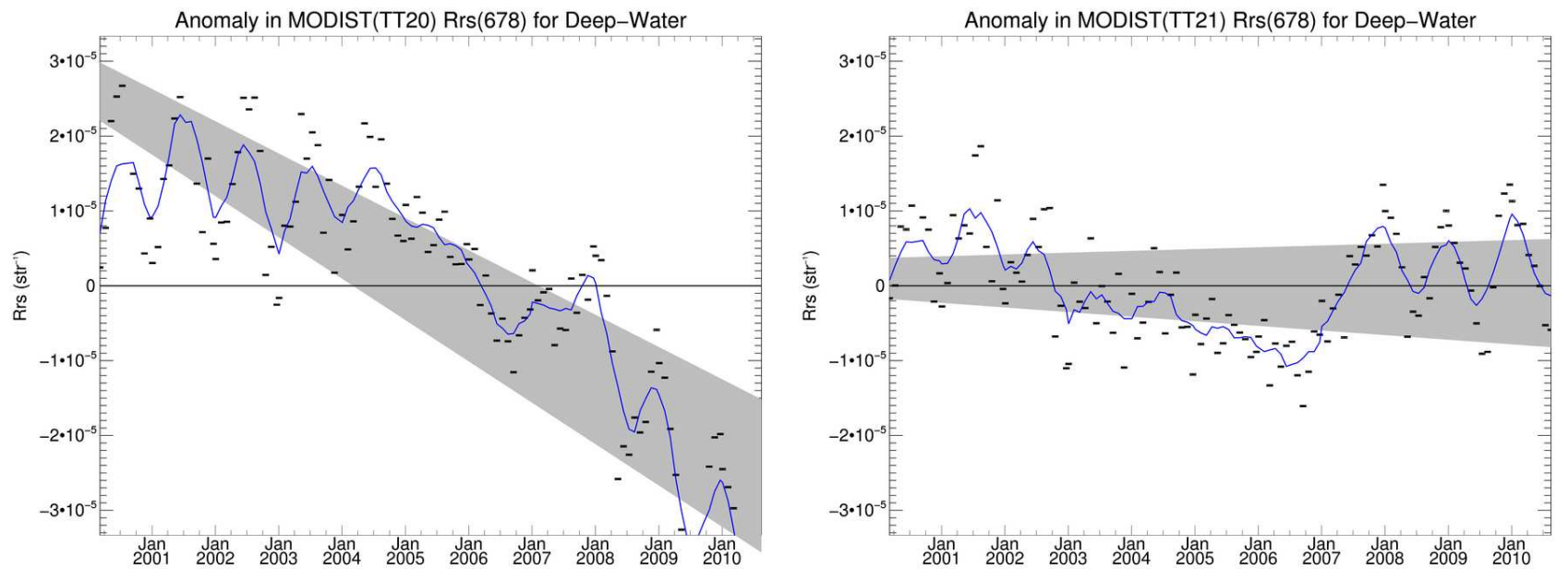

Figure 9. Anomaly plots of the MODIS Terra Rrs at $678 \mathrm{~nm}$ before (left) and after (right) corrections.

The fluorescence line height (FLH) product depends on the difference of the Rrs of bands 13 and 14. Without correction, a trend in band 14 showed a strong decrease over time, which affected the FLH product. The corrections removed the trend in band 14 (see Fig. 9), which significantly reduced the trend in the FLH product (see Fig. 10). The trends of band 13 were not significantly changed by the correction (not shown).

The global average chlorophyll of MODIS Terra R2010.0 now has a very similar trend to the SeaWiFS product in oligotrophic (low chlorophyll) regions, see Fig. 11, with a bias of about 5-10\% (MODIS Terra being lower). However, in eutrophic (high chlorophyll) regions, the MODIS Terra global average chlorophyll decreases relative to SeaWiFS, especially after 2005. At the end of 2010, the difference has reached about $30 \%$. The trends of the green bands of MODIS Terra and SeaWiFS are quite consistent in eutrophic regions, but the blue bands of MODIS Terra increase over time relative to SeaWiFS in eutrophic regions (not shown in this paper). The reason for this inconsistency is not known. Note that the $m_{13}$ of band 8 (see Fig.2) show increased noise at the end of the mission. Fig. 11 also shows that in the first half of the mission, the mesotrophic region has a larger bias than either the eutrophic or the mesotrophic region, which is unexpected.

The OBPG evaluates striping and scan angle dependency of the MODIS Terra ocean color products by 

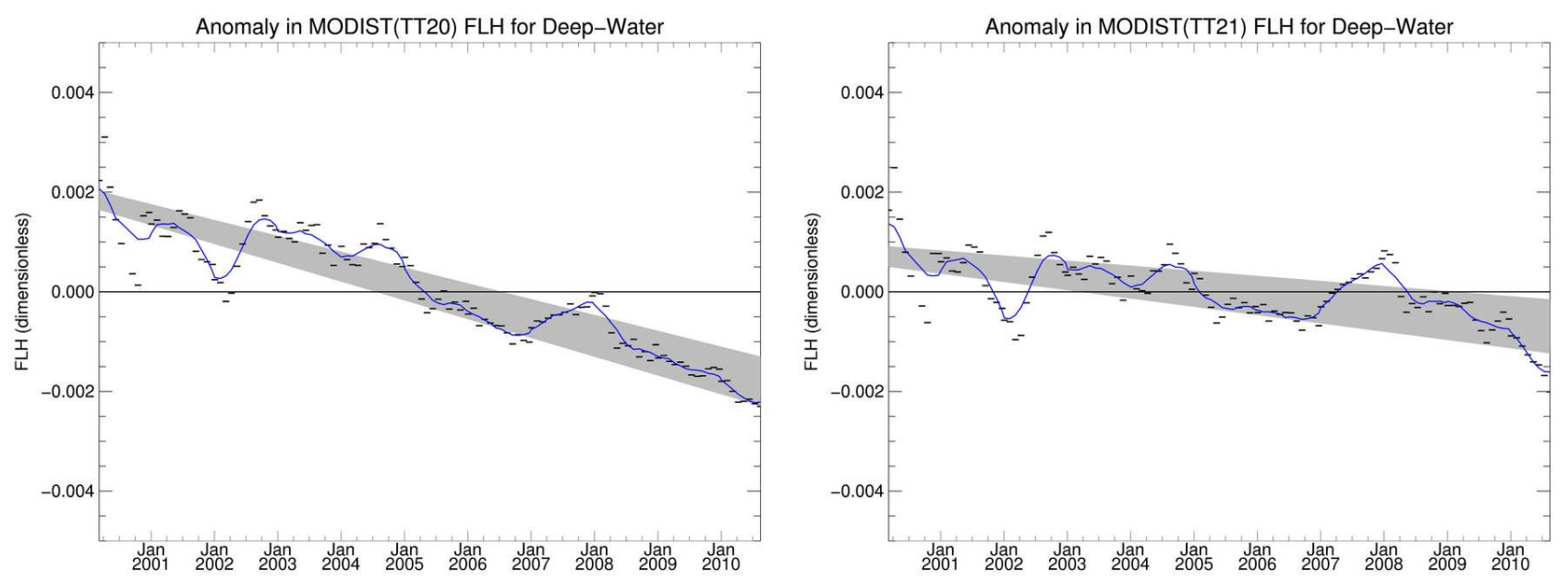

Figure 10. Anomaly plots of the MODIS Terra FLH before (left) and after (right) corrections.

plotting the global average of the MODIS Terra L2 products from one day divided by the corresponding 15-day L3 product as a function of scan angle (see Franz et al. ${ }^{5}$ for further details). The results for the 443nm waterleaving radiances for two different days are shown in Fig. 12 before the correction and after the correction. It can be seen that striping has been reduced significantly for both days, and the strong scan angle dependency in 2007 has been removed by the correction. However, it can be seen that there is a slight bias between the two mirror sides in 2007 for most of the scan angles, so some residual striping remains.

\section{CONCLUSIONS}

The OBPG completed the MODIS Terra ocean color reprocessing R2010.0 in January 2011. Significant calibration corrections were derived (and applied) using SeaWiFS data, with largest corrections for the shorter wavelengths. Relatively small corrections were derived for the red bands using MODIS Aqua data as truth. The accuracy of the trends in the MODIS Terra ocean color products is therefore directly related to the temporal calibration accuracy of SeaWiFS and MODIS Aqua. The polarization sensitivity derived for the shortest wavelengths (412nm and $443 \mathrm{~nm}$ ) is extremely large, with values up to $40 \%$. This should be seen in relation to the prelaunch performance that showed polarization sensitivity of less than $6 \%$. The atmospheric correction algorithm is not expected to work with its usual accuracy for such large polarization sensitivities. ${ }^{8}$ Therefore, users of MODIS Terra data should be cautious when using products based on the short wavelengths, especially in the later part of the mission. In general, the L3 products show good agreement with SeaWiFS and MODIS Aqua for the global averages, but significant regional and short time scale inconsistencies may remain.

Most of the MODIS Terra ocean color products are also produced from SeaWiFS and MODIS Aqua data. Although the majority of scientific users will continue to use SeaWiFS and MODIS Aqua data because of their superior radiometric characteristics, some users will benefit from the additional coverage (e.g. cloud cover related) that MODIS Terra can provide.

Furthermore, since the FLH product cannot be produced by SeaWiFS, the MODIS Terra reprocessing R2010.0 provides an opportunity to study remotely sensed chlorophyll fluorescence starting from February 2000, thus extending the previously available time series from MODIS Aqua by two years.

Other reasons to use MODIS Terra instead of SeaWiFS may include an increased signal-to-noise ratio, higher spatial resolution for the MODIS $1 \mathrm{~km}$ bands (SeaWiFS minimum spatial resolution in scan direction is $1.28 \mathrm{~km}$ (including tilt effects) for LAC and MLAC data, GAC data is subsampled), access to the higher resolution MODIS land bands $(500 \mathrm{~m}$ or $250 \mathrm{~m})$, or the availability of simultaneously measured sea surface temperature.

The corrections presented in this paper have been derived using SeaWiFS data, which has ceased operations in December 2010. It is technically straightforward to substitute MODIS Aqua for SeaWiFS. However, even for 

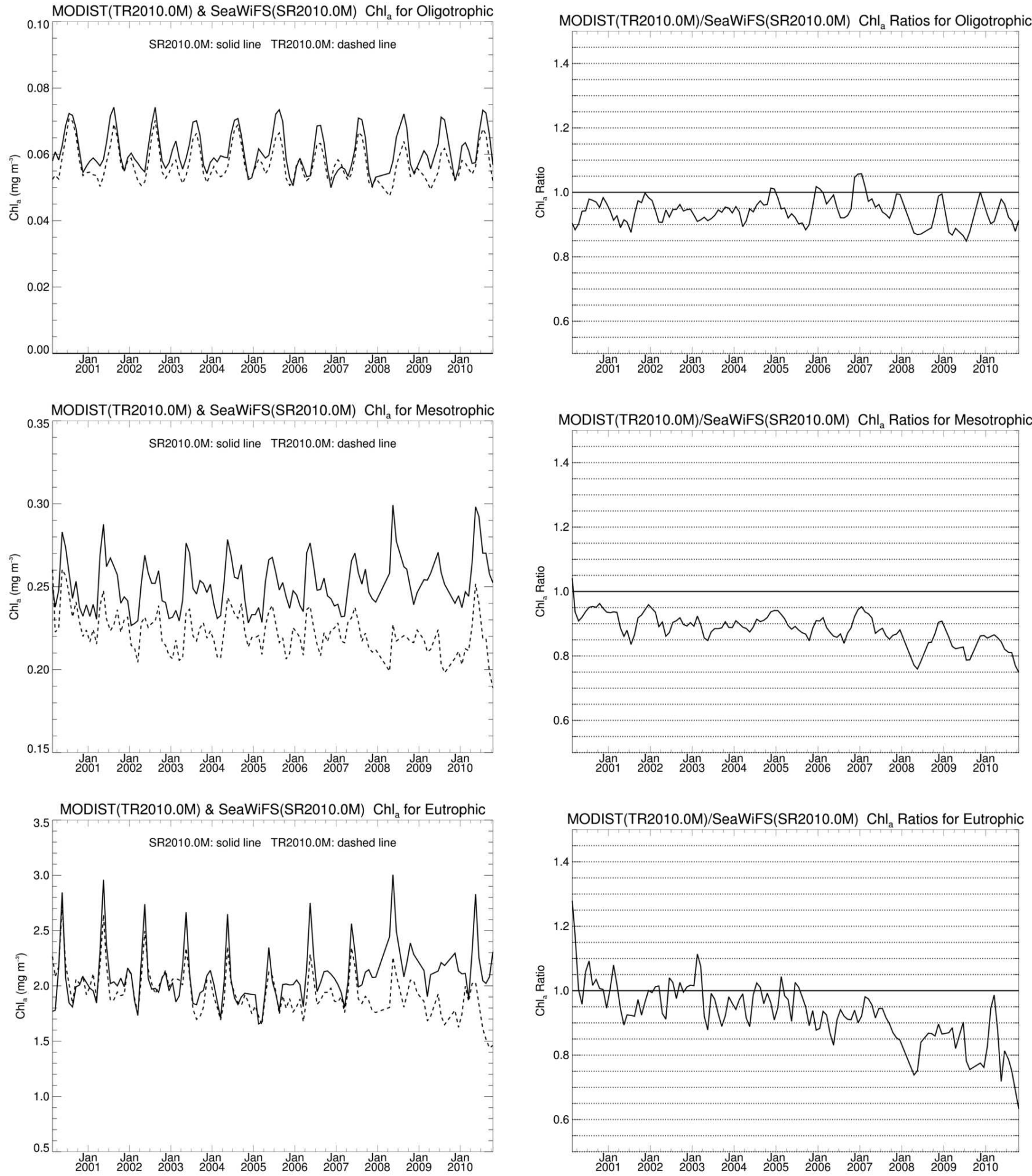

Figure 11. Top left: Monthly global chlorophyll average of MODIS Terra (solid line) and SeaWiFS (dashed line) in oligotrophic regions. Top right: Ratio of MODIS Terra over SeaWiFS chlorophyll in oligotrophic regions. Middle row: same for mesotrophic region. Bottom row: same for eutrophic regions. 

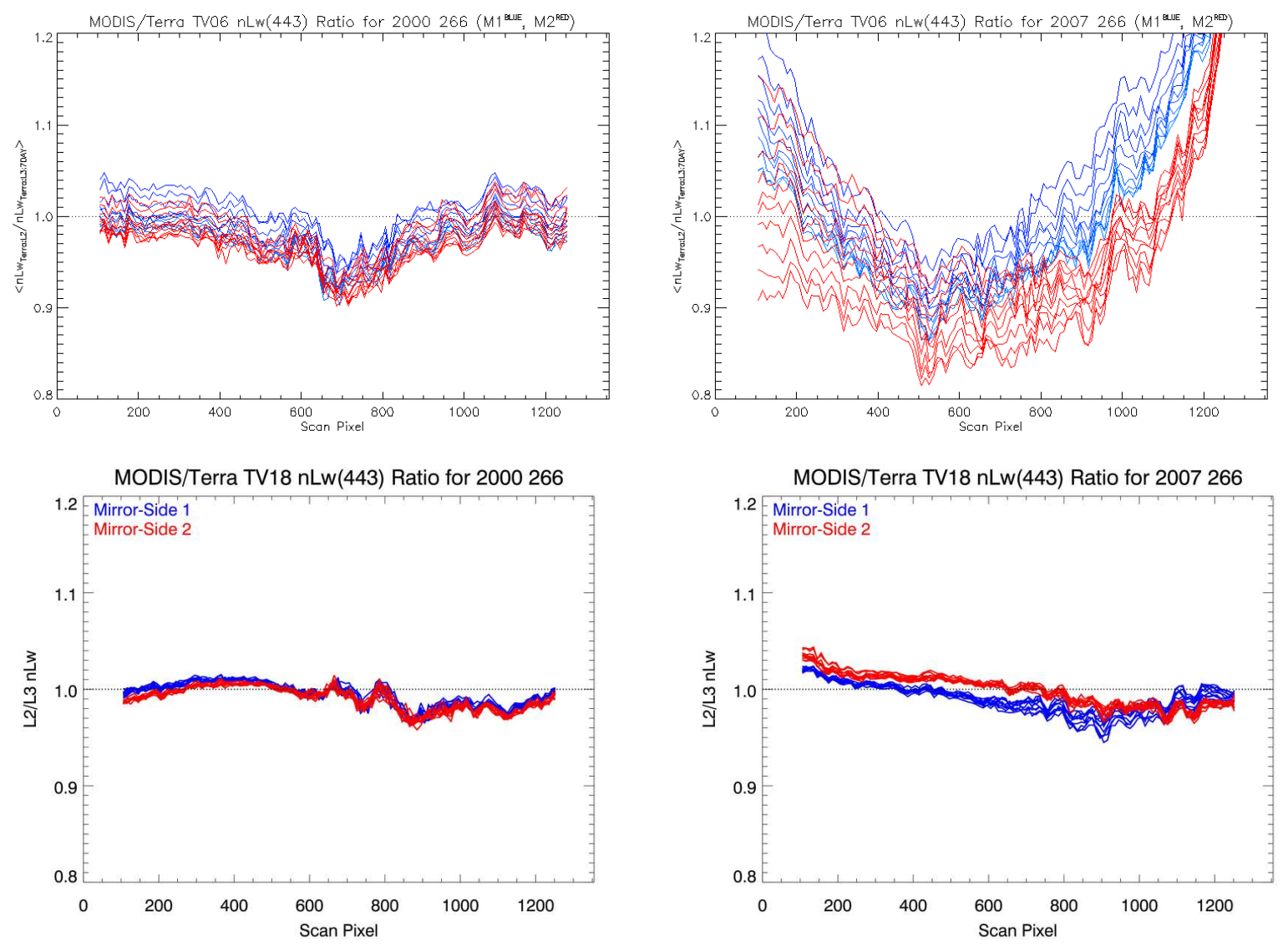

Figure 12. Top: Scan-angle dependence of water-leaving radiances at 443nm before corrections. Left: for day 266 of 2000. Right: for day 266 of 2007. Individual lines are for different detectors, blue for mirror side 1, red for mirror side 2 (usually lower than mirror side 1). Bottom: same after corrections.

MODIS Aqua, the short wavelength bands need to be corrected in the later part of the mission. ${ }^{13}$ An operational correction approach for MODIS Aqua without SeaWiFS needs to be established as of the writing of this paper. Even if this is successful, it should be noted that the OBPG plans to update the MODIS Terra corrections approximately twice a year, and therefore the most recent data is likely to suffer from suboptimal corrections, especially if the latest update occured several months ago.

It should also be noted that with the adjustments described in this paper, the MODIS Terra ocean color products are not an independent data record, because their long term trends are tied to those of SeaWiFS (and MODIS Aqua). However, the smoothing of the adjustments as described in table 2 largely limits the impact to longer term (annual) trends, regional or seasonal variations can still be unique in the MODIS Terra data set.

The corrections to the MODIS Terra calibration were derived using a vicarious technique that relies on atmospheric models over ocean. It is therefore not obvious that other disciplines (e.g. atmosphere or land) would benefit from these corrections. However, recent investigations ${ }^{16,17}$ indicate that especially the radiometric corrections from the $\mathrm{M}_{11}$ coefficients would lead to improved products for all disciplines.

\section{ACKNOWLEDGMENTS}

We want to thank our colleagues from OBPG, the MODIS Characterization Support Team, and Ewa Kwiatkowska for their support. This work was funded by the NASA MODIS Science Team. 


\section{REFERENCES}

[1] Barnes, W. L., Pagano, T. S., and Salomonson, V. V., "Prelaunch characteristics of the moderate resolution imaging spectroradiometer (MODIS) on EOS-AM1," IEEE Transactions on Geoscience and Remote Sensing 36(4), 1088-1100 (1998).

[2] Franz, B. A., Werdell, P. J., Meister, G., Bailey, S. W., Eplee, R. E., Feldman, G. C., Kwiatkowska, E., McClain, C. R., Patt, F. S., and Thomas, D., "The continuity of ocean color measurements from SeaWiFS to MODIS," Proc. SPIE 5882(1), 58820W, SPIE (2005).

[3] Xiong, X. and Barnes, W. L., "An overview of MODIS radiometric calibration and characterization," Advances in Atmospheric Sciences 23(1), 69-79 (2006).

[4] Sun, J., Xiong, X., Barnes, W., and Guenther, B., "MODIS reflective solar bands on-orbit lunar calibration," IEEE Transactions on Geoscience and Remote Sensing 45(7), 2383-2393 (2007).

[5] Franz, B. A., Kwiatkowska, E. J., Meister, G., and McClain, C. R., "Moderate Resolution Imaging Spectroradiometer on Terra: limitations for ocean color applications," Journal of Applied Remote Sensing 2, 023525 (2008).

[6] McClain, C. R., Feldman, G. C., and Hooker, S. B., "An overview of the SeaWiFS project and strategies for producing a climate research quality global ocean bio-optical time series," Deep-Sea Research II 51, 5-42 (2004).

[7] Kwiatkowska, E. J., Franz, B. A., Meister, G., McClain, C. R., and Xiong, X., "Cross calibration of ocean-color bands from Moderate-Resolution Imaging Spectroradiometer on Terra platform," Applied Optics 47(36), 6796-6810 (2008).

[8] Gordon, H. R., Du, T., and Zhang, T., "Atmospheric correction of ocean color sensors: analysis of the effects of residual instrument polarization sensitivity," Applied Optics 36(27), 6938-6948 (1997).

[9] Sun, J. and Xiong, X., "MODIS polarization sensitivity analysis," IEEE Transactions on Geoscience and Remote Sensing 45(9), 2875-2885 (2007).

[10] Meister, G., Kwiatkowska, E. J., Franz, B. A., Patt, F. S., Feldman, G. C., and McClain, C. R., "ModerateResolution Imaging Spectroradiometer ocean color polarization correction," Applied Optics 44(26), 55245535 (2005).

[11] Gordon, H. R. and Wang, M., "Retrieval of water-leaving radiance and aerosol optical thickness over the oceans with SeaWiFS: A preliminary algorithm," Applied Optics 33, 443-452 (1994).

[12] Franz, B. A., Bailey, S. W., Werdell, P. J., and McClain, C. R., "Sensor-independent approach to the vicarious calibration of satellite ocean color radiometry," Applied Optics 46, 5068-5082 (August 2007).

[13] Meister, G., Franz, B. A., Kwiatkowska, E. J., and McClain, C. R., "Corrections to the calibration of MODIS Aqua ocean color bands derived from SeaWiFS data," IEEE Transactions on Geoscience and Remote Sensing, accepted (2011).

[14] Meister, G. and Franz, B. A., "Radiometric quality of the MODIS bands at 667 and 678nm," in [Earth Observing Systems XVI], Butler, J. J. and Xiong, J., eds. (2011).

[15] Brown, S. W., Flora, S. J., Feinholz, M. E., Yarbrough, M. A., Houlihan, T., Peters, D., Kim, Y. S., Mueller, J. L., Johnson, B. C., and Clark, D. K., "The Marine Optical BuoY (MOBY) radiometric calibration and uncertainty budget for ocean color satellite sensor vicarious calibration," Sensors, Systems, and NextGeneration Satellites XI 6744, 67441M, SPIE (September 2007).

[16] Jeong, M., Hsu, N. C., Kwiatkowska, E. J., Franz, B. A., Meister, G., and Salustro, C. E., "Impacts of cross-platform vicarious calibration on the Deep Blue aerosol retrievals for Moderate Resolution Imaging Spectroradiometer aboard Terra," IEEE Transactions on Geoscience and Remote Sensing, accepted (2011).

[17] Junqiang Sun, "RSB Calibration, Performance, and C6 issues." http://modis.gsfc.nasa.gov/sci_team/meetings/201105/ (2011). 